Produto \& Produção, vol. 7, n. 2, p. 13-26, out.2002

\title{
A inserção da aprendizagem de "loop duplo" no processo de desenvolvimento de produtos: uma análise crítica da abordagem do Planejamento Avançado da Qualidade do Produto (APQP)
}

\author{
Noel Torres Júnior, M.Eng. \\ Escola Politécnica da Universidade de São Paulo \\ Departamento de Engenharia de Produção \\ Dario Ikuo Miyake, Ph.D. \\ Escola Politécnica da Universidade de São Paulo \\ Departamento de Engenharia de Produção
}

\begin{abstract}
O Processo de Desenvolvimento de Produtos (PDP) tem sido objeto de pesquisa por um número crescente de trabalhos. Entretanto, relativamente poucos estudos têm sido realizados sobre a melhoria contínua do desempenho no PDP. Este artigo discute os principais fatores e restrições que influenciam o desempenho da organização na condução de atividades do PDP e delineia uma estrutura conceitual que relaciona as funções de planejamento, avaliação e melhoria das atividades que constituem este processo num contexto que favoreça a aprendizagem de "loop duplo". O modelo de Planejamento Avançado da Qualidade do Produto (APQP) é então discutido criticamente à luz da perspectiva conceitual apresentada.
\end{abstract}

Palavras-chave: processo de desenvolvimento de produto; APQP; aprendizagem de “loop duplo".

The Product Development Process (PDP) has been investigated as a research subject by an increasing number of works. However, relatively few studies have focused on the continuous improvement of performance in PDP. This article points out major strategic issues and constraints that influence the performance of an organization in PDP and delineates a conceptual framework aimed at supporting managers in planning, assessing, and improving development activities based on the Double Loop Learning concept. The application of Advanced Product Quality Planning (APQP) model is then critically discussed from the perspective of the proposed framework.

Keywords: product development process; APQP; double loop learning.

\section{Introdução}

O processo de desenvolvimento de produtos e processos deve ser encarado como um elementochave para o sucesso das empresas, pois a sobrevivência da empresa no longo prazo tende a depender cada vez mais da sua capacidade de desenvolver produtos e processos com velocidade e eficácia. Ao mesmo tempo, a empresa deve robustecer seu processo de desenvolvimento no sentido de torná-lo cada vez mais consistente e menos sujeito a variações significativas de desempenho. A grande questão não é mais saber se o processo de desenvolvimento de produtos e processos é estratégico para as empresas. Esta é uma questão já respondida. As organizações se defrontam agora com o desafio de compreender como criar, estruturar e robustecer o processo de desenvolvimento de produtos e processos (CLARK e WHEELWRIGHT, 1992).
Devemos considerar ainda que o desenvolvimento de produtos está sendo realizado numa nova economia. Segundo Castells (1999), uma nova economia informacional e global surgiu nas duas últimas décadas. Ela é informacional porque a produtividade e a competitividade de unidades ou agentes nesta economia dependem basicamente de sua capacidade de gerar, processar e aplicar, de forma eficiente, a informação baseada em conhecimentos. É global porque os mercados (o consumo e a circulação), e pelo lado da oferta (as atividades produtivas, assim como os recursos de capital, trabalho, matéria-prima, administração, informação e tecnologia) se organizam cada vez mais em escala global. É ambas porque a concorrência e a busca de produtividade ocorrem numa rede global de interação.

A sociedade se vê diante de um mundo em que a informação desempenha um papel cada vez mais relevante. As organizações são afetadas por esta 
revolução que influencia a própria competição, seja alterando a estrutura do setor, mudando as regras da competição, seja criando vantagens competitivas, de maneira a proporcionar novas formas de as empresas superarem os competidores; ou mesmo, dando origem a novos negócios dentro das próprias operações já existentes (PORTER e MILLAR, 1997).

Inseridas neste contexto, as áreas pertencentes às organizações empresariais são também afetadas por estas tendências. Em particular, o processo de desenvolvimento de produtos (PDP) também tem sido afetado por esta realidade e isso motiva a busca de um melhor entendimento do papel da aprendizagem na melhoria do desempenho no PDP. Com o propósito de contribuir neste esforço, este artigo incorpora os seguintes tópicos ainda pouco explorados na literatura de engenharia de produção:

- a aprendizagem de "loop duplo" no âmbito do PDP e sua importância para a melhoria do desempenho no processo de desenvolvimento;

- a necessidade de gerenciar adequadamente a atenção humana dentro do PDP;

- a contribuição que a aplicação de modelos referenciais de planejamento, organização e condução do PDP podem proporcionar para a promoção da melhoria contínua no PDP.

Uma revisão bibliográfica sobre estes pontos é apresentada e um quadro teórico é articulado de modo a fundamentar o delineamento de uma estrutura conceitual para a gestão da melhoria do desempenho do PDP. Esta estrutura conceitual é utilizada para analisar o sistema de Planejamento Avançado da Qualidade do Produto (APQP), um particular modelo referencial de reconhecida relevância nos meios industriais e científicos.

\section{O Processo de Desenvolvimento de Produtos}

O PDP deve ser estruturado levando-se em consideração as estratégias de negócio e de projeto adotadas pela empresa. Segundo Griffin e Page ${ }^{1}$ (ANSOFF, 1996 apud ANSOFF, 1957), as empresas podem ser divididas nas seguintes quatro categorias conforme sua estratégia de posicionamento no negócio:

- Empresas prospectoras que são as pioneiras em termos de mercados, produtos e tecnologia;
- Empresas analisadoras que monitoram cuidadosamente os competidores e freqüentemente conseguem rapidamente seguir os competidores trazendo inovações em termos de produto e/ou eficiência;

- Empresas protetoras que se limitam a manter um nicho seguro do mercado protegendo o mesmo através do estabelecimento de um diferencial em alguma(s) dimensão(ões) como qualidade, serviço ou preço;

- Empresas reativas que somente respondem às mudanças de mercado quando pressionadas.

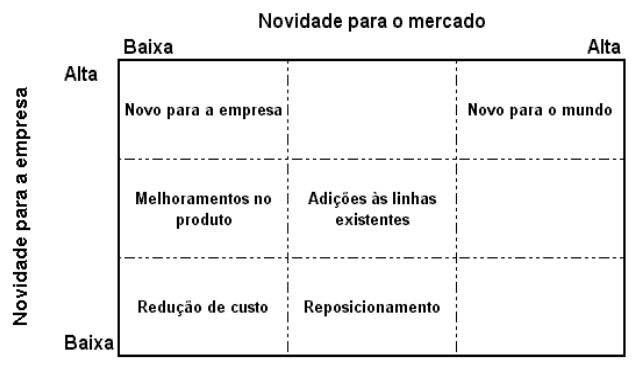

Figura 1 - Diferentes tipos de projeto segundo MILES e SNOW (1978 apud MILES e SNOW, 1996).

Quanto à estratégia de projeto, segundo Griffin e Page (MILES e SNOW, 1978 apud MILES e SNOW, 1996), os diferentes tipos de projetos podem ser agrupados em seis categorias conforme seguem (ver enquadramento na Figura 1):

- Produto novo para o mundo que cria um mercado completamente novo (novo para o mundo);

- Produto novo para a empresa que viabiliza sua entrada, pela primeira vez, num determinado mercado (novo para a empresa);

- Novos produtos que sejam adições às linhas de produtos existentes (adições às linhas existentes);

- Novos produtos que sejam melhorias ou revisões dos produtos existentes (melhoramentos no produto);

- Produtos existentes direcionados a novos mercados ou segmentos de mercados (reposicionamento);

- Novos produtos que têm performance similar aos existentes a um custo menor (redução de custo).

1 ANSOFF, H.I. Strategies for diversification. Harvard Business Review, Sept-Oct, 1957.

2 MILES, R.E. e SNOW, C.C. Organizational strategy, structure and process. New York: McGraw-Hill, 1978. 
Numa empresa, a estratégia de negócio dominante influencia sua estratégia de projeto. Por exemplo, uma empresa predominantemente do tipo prospectora terá, em seu portfólio de produtos, um percentual significativo de projetos do tipo "produto novo para a empresa" ou mesmo "produto novo para o mundo", conforme o setor que atua. Ou seja, a proporção de cada tipo de projeto dentro do portfólio de produtos da empresa está relacionada com sua estratégia de negócio predominante.

De modo semelhante, existe também uma relação entre as estratégias de negócio e de projeto com o próprio PDP. Por exemplo, um projeto do tipo "produto novo para o mundo" exigirá uma estrutura de recursos, uma forma de organização e um sistema de informação muito mais complexo que um projeto do tipo "redução de custo".

O desenvolvimento da discussão sobre a relação entre a maneira como o PDP é planejado e conduzido e seu desempenho requer uma descrição genérica. Silva et al. (2000) observam que alguns pontos são praticamente comuns para a caracterização de qualquer PDP. Para estes autores, os seguintes elementos constituiriam um modelo de referência para a condução de um PDP:

- Fases/Atividades: definem a evolução temporal de um processo de desenvolvimento de produto;

- Recursos: suportam as pessoas no desenvolvimento das atividades de desenvolvimento de produtos. Incluem conceitos, filosofias, métodos, técnicas, ferramentas e sistemas que podem ser aplicados em uma ou mais das atividades/fases do PDP;

- Organização: refere-se à estrutura organizacional responsável e executora das atividades deste processo bem como aos aspectos ligados às relações no trabalho;

- Informação: dimensão referente ao fluxo de informação existente neste processo, ou seja, os dados, sua estrutura e o formato como estes circulam.

O contexto das relações apresentadas nesta seção pode ser vizualizado na Figura 2.

\section{Planejamento Avançado da Qualidade do Produto (APQP)}

Na literatura sobre o PDP, muitos trabalhos foram dedicados ao tema do planejamento e organização das atividades-chave que constituem o ciclo de desenvolvimento. O exame destes trabalhos revela que existem diversas abordagens para a divisão do PDP em diferentes etapas e que não seria pertinente eleger um modelo que possa ser genericamente apontado como ideal.

No entanto, face à sua crescente disseminação no meio empresarial e ao grande detalhamento das atividades e ferramentas indicadas para cada fase, o presente trabalho se aprofunda na discussão do modelo que é referenciado pela norma QS-9000, denominada de Planejamento Avançado da Qualidade do Produto (APQP). ${ }^{3}$

Segundo Abraham (1998), o Planejamento Avançado da Qualidade do Produto (APQP) foi desenvolvido em conjunto pela Ford, GM e Chrysler, em julho de 1994, com o objetivo de orientar seus fornecedores no esforço de melhoria de seus processos de planejamento avançado da qualidade. O APQP fornece um sistema estruturado que define e estabelece os procedimentos necessários para:

- assegurar que o produto satisfaça o cliente;

- facilitar a comunicação entre os envolvidos (fornecedor e montadora);

- garantir o cumprimento dos procedimentos e das atividades nos prazos;

- minimizar riscos e custos associados a problemas de qualidade do projeto do produto e processo, com base na abordagem do trabalho em equipe.

Na perspectiva do APQP, o PDP é composto de cinco etapas conforme seguem (GONZALEZ e MIGUEL, 2000):

i. Planejamento e Definição do Programa-Determinação das necessidades e expectativas dos clientes de forma a planejar e definir um programa de qualidade;

ii. Projeto e Desenvolvimento do Produto - Planejamento e projeto do produto, e construção e teste

\footnotetext{
3 A norma QS-9000 é a harmonização do Manual de Qualidade Assegurada de Fornecedores da Chrysler, Norma de Sistema da Qualidade Q-101 da Ford, e Metas para Excelência da General Motors, com a contribuição dos Fabricantes de Caminhões. A norma QS-9000 é complementada por seis manuais técnicos de referência. São eles: Measurement Systems Analysis - MSA (guia para análise do sistema de medição), Statistical Process Control - SPC (guia de controle estatístico de processo), Quality System Assessment - QSA (guia para avaliação do sistema da qualidade), Failure Mode and Effects Analysis - FMEA (guia de FMEA de projeto e processo), Production Part Approval Process - PPAP (manual para aprovação das primeiras peças de produção) e Advanced Product Quality Planning - APQP (guia para o planejamento do desenvolvimento do produto e guia para elaboração do plano de controle).
} 
do protótipo, com o objetivo de assegurar que as especificações próximas das finais atendam à Voz do Cliente;

iii. Projeto e Desenvolvimento do Processo - Desenvolvimento de um sistema de manufatura e seus respectivos planos de controle para obter produtos de qualidade;

iv. Validação do Produto e do Processo - Validação do processo de manufatura através da avaliação de uma corrida piloto de produção;

v. Retroalimentação, Avaliação e Ação Corretiva -O planejamento da qualidade não termina com a valida- de desenvolver produtos e processos de uma maneira "extraordinária" representa, na atual conjuntura, uma valiosa arma competitiva. Clark e Wheelwright (1992) enumeram três grandes forças que tornam as atividades de desenvolvimento cada vez mais importantes:

- Intensa competição internacional: cada vez mais aumenta o número de empresas capazes de competir em nível "classe mundial"; conseqüentemente, a competição vai se tornando cada vez mais agressiva.

- O mercado tem-se tornado mais fragmentado: os clientes estão mais sensíveis às diferenças entre os produtos e sentem-se mais atraídos por

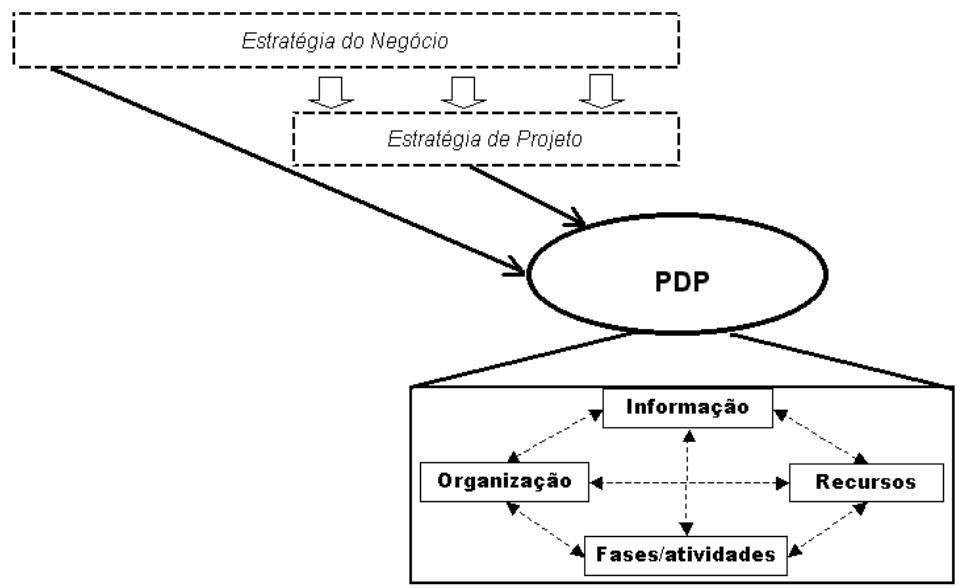

Figura 2 - Relações entre o PDP e as estratégias de negócio e de projeto.

ção do processo e sua instalação. A avaliação da efetividade do esforço de planejamento da qualidade do produto deve ser feita com foco na redução da variação, na satisfação do cliente, na melhoria da qualidade e do custo da entrega e assistência técnica.

A norma QS-9000 não será mais utilizada a partir de Dezembro de 2006 e será substituída pela norma ISO/ TS-16949. No entanto, para os fornecedores das montadoras Ford, GM e Daimler-Chrysler, os manuais técnicos como o do APQP e do Plano de Controle continuarão sendo referenciados pela ISO/TS-16949 (MUNRO, 2002; LUPO, 2002).

\section{Elementos para a melhoria do desempenho no contexto do Processo de Desenvolvimento de Produtos}

No ambiente turbulento atual, as competências em desenvolvimento de produto e processo tornaram-se um ativo organizacional com impacto significativo na definição da competitividade das empresas. Ser capaz produtos que fornecem soluções para suas necessidades e problemas específicos.

- Grande e rápida mudança nas tecnologias: o crescimento do conhecimento científico e a evolução tecnológica têm criado novas opções para o atendimento das diversas e crescentes necessidades dos mercados, aumentando as soluções disponíveis para engenheiros e profissionais de marketing na busca por novos produtos. As novas tecnologias em áreas como materiais, eletrônica e biologia têm, muitas vezes, mudado a natureza da competição existente nestas áreas.

De forma semelhante, Pine II (1994) destaca a necessidade de as empresas desenvolverem, produzirem, comercializarem e entregarem produtos com suficiente variedade e personalização, atendendo de modo cada vez mais customizado o mercado. Tal padrão de demanda tem induzido uma gradual diminuição dos ciclos de desenvolvimento e de vida dos produtos. Estas tendências têm forçado as organizações a aprimorarem seus processos de desenvolvimento de produtos de modo a torná-los mais ágeis, eficientes e robustos. 
Estas forças têm atuado nos mais variados setores industriais, afetando até mesmo indústrias maduras onde os ciclos de vida são historicamente longos, a tecnologia já está madura e o mercado estável. Portanto, torna-se fundamental implementar uma estratégia que possibilite levar adiante o melhoramento contínuo do desempenho do PDP.

Nesta direção, a presente seção examina as seguintes questões fundamentais na busca deste objetivo:

- O papel da gestão do conhecimento no PDP e, de modo mais específico, discute o que caracterizaria um sistema de aprendizagem de "loop duplo" no mesmo;

- A necessidade de gerenciar adequadamente a escassez de atenção das pessoas, para que a aprendizagem ocorra dentro do PDP;

- O que se entende por melhoria de desempenho no PDP.

Finalmente, elabora uma estrutura conceitual em que a aprendizagem de "loop duplo" é inserida no contexto do planejamento, condução e avaliação de projetos de desenvolvimento como um catalisador da melhoria contínua das atividades de desenvolvimento.

\subsection{Gestão do conhecimento no Processo de Desenvolvimento de Produtos}

Conforme indica o Figura 3, o tema gestão do conhecimento tornou-se mais presente nos últimos anos dentro do PDP.

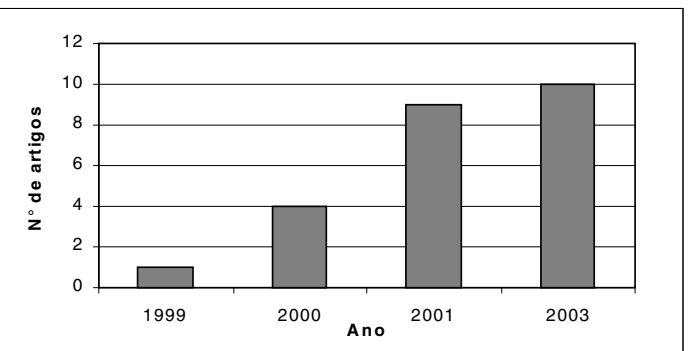

Figura 3 - Número de artigos sobre gestão do conhecimento no PDP apresentados no Congresso Brasileiro de Gestão de Desenvolvimento de Produto.

Fontes: Anais do $1^{\circ}, 2^{\circ}, 3^{\circ}$ e $4^{\circ} \mathrm{CBGDP}$.

Dentre vários fatores, o crescente interesse pelo tema no PDP pode ser relacionado com a intensificação da competição no mercado que motiva as empresas a melhorarem suas competências de desenvolvimento de produto e criar/agregar outras ao longo do tempo. O fortalecimento das competências atuais e a criação de novas competências dependem da capacidade de estabelecer uma efetiva gestão do conhecimento. Dentro deste contexto, segundo Probst et al. (2002), a gestão do conhecimento lida com os seguintes grandes processos dentro da empresa:

- Identificação do conhecimento: tanto os conhecimentos internos quanto externos não estão automaticamente visíveis, portanto, as organizações devem analisar e descrever o ambiente de conhecimento da empresa;

- Aquisição do conhecimento: as empresas importam conhecimento de várias fontes externas como especialistas, outras empresas, clientes, fornecedores, concorrentes e parceiros;

- Desenvolvimento do conhecimento: consiste no desenvolvimento de novas habilidades, novos produtos, idéias melhores e processos mais eficientes. Inclui a criação de competências que ainda não existem dentro ou fora da empresa;

- Partilha ou distribuição do conhecimento: significa a transferência de conhecimento entre um determinado grupo de funcionários, entre indivíduos, dentro de equipes ou grupos de trabalho;

- Utilização do conhecimento: consiste na sua aplicação e visa garantir que a empresa utilize efetivamente o seu know-how;

- Retenção do conhecimento: objetiva construir a "memória" da empresa, possibilitando que grande parte do conhecimento não seja perdido em conseqüência da rotação ou saída de pessoas.

Para que seja possível tratar o conhecimento como recurso que possa ser gerido e explorado através deste conjunto de processos, a administração deve ainda acrescentar dois elementos construtivos na organização, quais sejam: uma estrutura para o estabelecimento de metas de conhecimento e um mecanismo de avaliação (ver Figura 4).

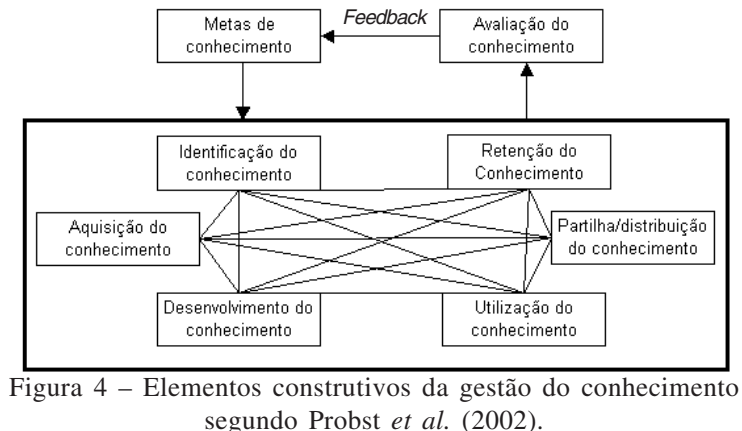


A gestão do conhecimento no PDP envolve várias atividades que lidam com os processos listados por Probst et al. (2002). Várias características presentes no PDP tornam o processo de gestão do conhecimento mais complexo. Exemplos dessas características são apresentados a seguir:

- É composto de atividades intensivas em conhecimento (tanto explícito como tácito);

- É um processo pouco estruturado, composto de atividades muitas vezes simultâneas e que interagem continuamente;

- Cada ciclo de projeto apresenta desafios próprios e, em cada ciclo, o conhecimento sobre o projeto deve ser disseminado rapidamente dentro da organização;

- É um processo multidisciplinar que necessita integrar o conhecimento de vários especialistas e funções.

Em face à complexidade da gestão de conhecimento existente no PDP, este trabalho se limita a focalizar os processos de retenção, distribuição e utilização de conhecimentos dentro do PDP. Esses três processos são vistos sob a ótica da estruturação de práticas que permitam uma aprendizagem reflexiva no mesmo. Para isto, resgata o conceito de aprendizagem de "loop duplo" descrito na seção seguinte.

\subsection{Aprendizagem de "loop duplo"}

Segundo Argyris (1976; 1977), a aprendizagem organizacional pode ser dividida em aprendizagem de "loop único" ou "loop duplo". A aprendizagem de "loop único" ocorre quando erros são detectados e corrigidos mas sem implicar em nenhum impacto efetivo na maneira como as atividades são planejadas e executadas nas organizações. A aprendizagem de "loop duplo" inclui além da detecção e correção dos erros, o questionamento e modificação dos objetivos, políticas, normas e procedimentos vigentes. No contexto de um PDP, a aprendizagem de "loop único" implica apenas na realização de atividades do tipo "apagar incêndios", ${ }^{4}$ na medida que o desenvolvimento avança e problemas vão sendo identificados, enquanto que a aplicação da aprendizagem de "loop duplo" promove a sua contínua melhoria por meio de uma sistemática de revisão e melhoramento das atividades.

É preocupante que mesmo tendo decorrido quase três décadas desde a publicação desse conceito, grande número de empresas se encontram ainda trabalhando com a aprendizagem no modo de "loop único". Para uma organização caminhar para a aprendizagem de "loop duplo" várias ações e atitudes devem ser desenvolvidas. Neste contexto, baseando-se em estudos de caso, Hameri e Nihtilã (1998) listam alguns requisitos que devem estar presentes no PDP para que a aprendizagem de "loop duplo" ocorra:

- As etapas do desenvolvimento de produtos devem estar claramente definidas e documentadas, permitindo, também, que as mudanças ocorridas em cada produto e projeto sejam retidas. Não é suficiente que o PDP esteja apenas formalizado e documentado, ele também deve estar estruturado de modo a assegurar que o PDP proposto pela organização suporte efetivamente as atividades diárias e os papéis desempenhados pelos indivíduos durante o desenvolvimento de produtos. Cabe à gerência zelar pela observação destes cuidados no PDP;

- A gerência deve garantir que, em todos os níveis organizacionais, exista um entendimento comum do PDP. Neste sentido, desde as fases iniciais de desenvolvimento, deve-se estabelecer claramente os objetivos de desempenho para cada atividade e membro do time, detalhando-os em um nível adequado de compreensão;

- Na fase de conceituação, nas fases inicial e final do desenvolvimento, e também no follow-up, a gerência deve primordialmente propiciar um clima para a efetiva participação e envolvimento de todo o time. Após o estabelecimento do conceito do produto e com o avançar das atividades, a gerência deve se concentrar nas atividades de controle, de modo a assegurar o cumprimento dos planos e metas.

- Deve existir, para todos os membros do time, uma contínua coleta e análise de dados referentes ao desempenho das atividades de desenvolvimento. Isto demanda naturalmente um esforço extra por parte da empresa, e requer que a mesma propicie recursos (técnicas, métodos, ferramentas e sistemas) e tempo para a devida realização destas atividades. Cada membro do time de desenvolvimento deve estar motivado e apto para documentar suas atividades, coletar os dados para avaliar seu desempenho e tomar ações pertinentes na ocorrência de problemas.

Para que a aprendizagem de "loop duplo" seja inserida no âmbito do PDP de uma organização, esta deve empreender esforços para que a aprendizagem também ocorra nos demais processos e áreas existentes.

4 Entende-se por ações do tipo "apagar incêndios", ações caracterizadas pela alocação não prevista de projetistas e/ou outros recursos para consertar problemas descobertos tardiamente no desenvolvimento. 
Vários esforços devem ser realizados nesta tarefa. Dentro deste objetivo, Nevis et al. (1995) $)^{5}$ identificaram dez fatores facilitadores que induzem ou dão suporte à aprendizagem:

- Imperativo da varredura minuciosa: a organização deve empreender esforços para sistematicamente realizar uma varredura minuciosa do ambiente;

- Existência de lacunas de desempenho: o feedback é essencial para a avaliação. Particularmente, quando revela um resultado inferior ou fracasso, a análise de suas causas frequientemente proporciona novos insights e conduz à experimentação e ao desenvolvimento de novas habilidades. A consciência da existência de uma lacuna de desempenho é importante porque motiva a organização a reconhecer que a aprendizagem precisa ocorrer ou que algo já aprendido pode não estar funcionando bem. Uma razão pela qual organizações bem estabelecidas com histórico de sucesso duradouro podem, paradoxalmente, deixar a desejar em aprendizagem sistêmica é que passam por longos períodos em que o feedback é predominantemente positivo. A falta de evidências nãoconfirmadoras é uma barreira para a aprendizagem;

- Preocupação com a medição: a organização deve desenvolver métricas e realizar medições para dar suporte à aprendizagem;

- Mentalidade experimental: a organização deve dar ênfase à experimentação em bases correntes;

- Clima de abertura: os limites em torno do fluxo de informação devem ser permeáveis de tal modo que as pessoas possam fazer suas próprias observações. Grande parte da aprendizagem informal é uma função das interações diárias entre as pessoas, em sua maioria não planejadas. Além disso, a aprendizagem é promovida pela oportunidade de reunião com outros grupos e níveis mais altos da gerência. As pessoas precisam de liberdade para expressar seus pontos de vista através do desacordo legítimo e do debate. Outro aspecto crítico é o grau com que erros são compartilhados e não ocultados;

- Educação contínua: existência de um compromisso com a educação no longo prazo em todos níveis da organização. Deve haver um sentimento patente de que a aprendizagem e o treinamento prático nunca terminam;
- Variedade operacional: existem diferentes maneiras para se atingir os objetivos de trabalho. Uma organização que dá suporte a variações de estratégias, políticas, processos e estruturas de pessoal tem mais facilidade para se readaptar caso surjam problemas imprevistos. Ela conta com mais alternativas de ação e talvez ofereça uma riqueza maior de estilos e de interpretações a todos seus membros. Isso ajuda a enriquecer a aprendizagem futura de uma forma que seria impossível com uma abordagem simplificada;

- Advogados múltiplos: quanto maior o número de adeptos que promovam a idéia nova, mais rápida e extensivamente a aprendizagem ocorrerá. Mais ainda, num sistema eficaz, qualquer membro deve poder atuar como um agente de conscientização e da melhoria ou como advogado do desenvolvimento de novas competências. Desta forma, são possíveis tanto as iniciativas de cima para baixo, quanto as de baixo para cima;

- Liderança envolvida: a liderança em todos os níveis organizacionais deve estar engajada na implementação da visão. Os líderes somente poderão obter dados importantes e fornecer poderosos modelos de desempenho através do envolvimento direto que reflita coordenação, visão e integração;

- Perspectiva sistêmica: os participantes-chave devem pensar na interdependência das variáveis organizacionais em termos abrangentes. Isto envolve o grau com que gerentes verificam se as causas de suas dificuldades estão nos próprios sistemas internos em vez de atribuí-las a fatores externos.

\subsection{A Economia da Atenção}

Na conjuntura atual, a discussão da aprendizagem no PDP não pode omitir um problema que vem se agravando cada vez mais nas organizações: a insuficiência de atenção humana. Segundo Davenport e Beck (2001), a humanidade encontra-se na era da Economia da Atenção. ${ }^{6}$ Tem sido cada vez mais crítico às empresas conquistar e preservar a atenção de atores como consumidores, acionistas e empregados, além de saber distribuir a própria atenção perante tantas opções atraentes e tanta sobrecarga de informação. As tecnologias modernas continuarão cada vez mais acessíveis, oferecendo novas e fascinantes características que prometem melhorar os nossos contextos de informação, mas elas redundarão em maiores necessidades de atenção.

$5 \mathrm{Na}$ tentativa de compreender o que seria uma organização que aprende, os autores realizaram observações intensivas no campo em quatro empresas: Motorola, MIC, EDF e Fiat.

6 O termo "Economia da Atenção" foi cunhado por estes autores para caracterizar esse novo contexto em que o capital, o trabalho, a informação e o conhecimento são fatores relativamente abundantes, o que atenua as dificuldades para se começar um negócio, conquistar acesso a clientes e mercados, desenvolver uma estratégia, montar um site na web etc. Já a atenção humana, tem se tornado um recurso cada vez mais escasso. 
Neste novo contexto, o PDP concorre com outras atividades em busca da atenção das pessoas envolvidas. A aprendizagem no PDP para ser efetiva necessita do tempo e da dedicação das pessoas envolvidas no processo. Faz-se necessário implementar estratégias que habilitem as atividades do PDP a concorrer eficazmente com atividades de outros processos existentes na empresa para atrair a atenção das pessoas afetadas.

Davenport e Beck (2001) sugerem algumas abordagens para lidar com o problema da escassez de atenção:

- Utilizar a tecnologia para defender seus recursos de atenção contra intromissões indesejadas. Para este fim, dispositivos para peneiramento de informações especialmente adaptados às mídias existentes podem ser aplicados (ex.: dispositivos de filtragem de $e$-mails, dispositivos de filtragem ou bloqueio de chamadas telefônicas etc.);

- Aproveitar as lacunas de atenção ambiental existentes (situações em que existe uma ampla oferta de atenção, como em salas de espera, no refeitório, no trânsito etc.), aplicando a informação neste momento;

- Utilizar a tecnologia para tornar as mensagens enviadas mais customizadas às necessidades das pessoas;

- Utilizar a tecnologia para estruturar o conteúdo da informação de maneira que a atenção seja facilmente conquistada. Isto pode ser obtido através da utilização de técnicas de comunicação na elaboração da informação. Por exemplo, podese usar recursos visuais que façam mudanças no conteúdo, no formato, no tom, no nível de envolvimento e assim por diante para atrair e reter a atenção do usuário da informação.

\subsection{Melhoria do desempenho do Processo de Desenvolvimento de Produto}

Clark e Fujimoto (1991), ao estudarem o desenvolvimento de produtos no setor automobilístico, definiram que o desempenho do PDP que afeta a capacidade do produto em atrair e satisfazer os consumidores está assentada em três aspectos: (a) lead time, (b) qualidade do produto desenvolvido e (c) produtividade. Segundo estes autores, o lead time é o tempo gasto no projeto, da concepção ao lançamento do produto comercial, mas essa dimensão não é incorporada à produtividade. A produtividade em um dado projeto é então definida pelo nível de recursos requeridos para seu desenvolvimento, incluindo horas trabalhadas, materiais usados na construção dos protótipos e quaisquer serviços que a empresa, por ventura, use.

De acordo com McGrath (1996), a produtividade no PDP é basicamente definida em função dos seguintes fatores:

- tempo do ciclo de desenvolvimento,

- nível de perdas no desenvolvimento,

- grau de utilização dos recursos, e

- potencial de atrair e reter talentos técnicos.

Por esta perspectiva, seria possível melhorar a produtividade no PDP buscando-se a redução do tempo de desenvolvimento, a redução dos casos de cancelamento ou redirecionamento de projetos, e pela alocação das pessoas mais capazes, criativas e produtivas.

\subsection{Uma estrutura conceitual de gestão do PDP com aprendizagem de "loop duplo"}

Os elementos apresentados nesta seção podem ser relacionados tal como na Figura 5 de modo a articular uma estrutura conceitual para a consideração da gestão do PDP com aprendizagem de "loop duplo" no contexto competitivo exposto.

Os seguintes pontos constituem a estrutura conceitual proposta:

- A melhoria do desempenho no contexto do PDP representa um resultado direto da articulação dos seus elementos constituintes. Como as estratégias de negócio e de projeto afetam a formação desses elementos, o desempenho do PDP deve também ser considerado como um processo sujeito a essas condições contextuais.

- O conceito de melhoria contínua, adotado na gestão de sistemas de produção, pode ser estendido às atividades de desenvolvimento buscando-se o aprimoramento contínuo do PDP por meio da aprendizagem de "loop duplo". A sua adoção tem um impacto positivo em vários elementos. Obtém-se uma melhor utilização dos recursos porque os erros e problemas são continuamente reduzidos. Obtém-se uma redução do número de projetos cancelados ou que necessitam ser redirecionados devido ao aumento do conhecimento sobre PDP. Melhorase a habilidade para atrair e reter os talentos técnicos porque o ambiente de trabalho torna-se mais motivador. Assim, o lead time, a qualidade do produtos desenvolvidos e a produtividade do PDP melhorariam em decorrência dos efeitos promovidos pela aprendizagem de "loop duplo". 


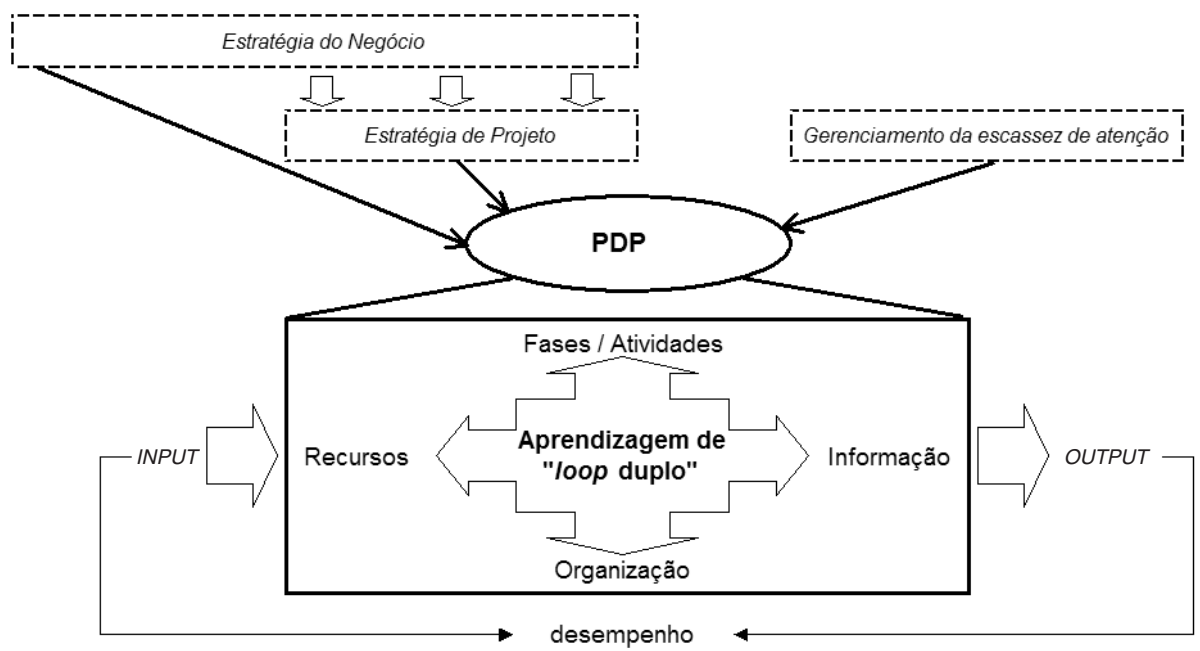

Figura 5 - Estrutura Conceitual de gestão do PDP com aprendizagem de "loop duplo"

\begin{tabular}{|c|c|c|c|c|c|c|c|}
\hline \multirow{3}{*}{ 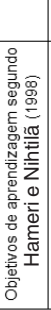 } & \multicolumn{2}{|c|}{ Fase } & \multirow{2}{*}{$\begin{array}{l}\text { Conceituação } \\
\text { Gerar um entendimento } \\
\text { comum do processo de } \\
\text { desenvolvimento e das } \\
\text { métricas do processo }\end{array}$} & \multicolumn{3}{|c|}{ Execução } & \multirow{2}{*}{\begin{tabular}{|c|} 
Follow-up \\
Avaliar a performance do \\
processo de \\
desenvolvimento, identificar \\
áreas chaves para melhoria e \\
implementar modificações
\end{tabular}} \\
\hline & 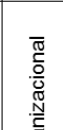 & 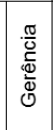 & & \multicolumn{3}{|c|}{ Controle e feedback on-line } & \\
\hline & $\frac{\bar{o}}{\bar{D}}$ & $\stackrel{\infty}{\stackrel{\infty}{\xi}}$ & $\begin{array}{l}\text { Certificar-se que os objetivos } \\
\text { principais e especificos } \\
\text { estejam bem entendidos }\end{array}$ & \multicolumn{3}{|c|}{ Não demorar em responder/atender aos problemas } & \begin{tabular}{|c|} 
Obter sugestões para \\
desenvolvimento e acumular \\
experiência com as lições \\
aprendidas
\end{tabular} \\
\hline & & & \multicolumn{5}{|c|}{ Etapas de Desenvolvimento e Projeto do Produto segundo o APQP } \\
\hline \multicolumn{3}{|c|}{$\begin{array}{l}\text { FASES } / \\
\text { ATIVIDADES }\end{array}$} & $\begin{array}{l}\text { 1) Planejamento e } \\
\text { Definição do } \\
\text { Programa }\end{array}$ & \begin{tabular}{|c|} 
2) Projeto e \\
Desenvolvimento de \\
Produto
\end{tabular} & $\begin{array}{l}\text { 3) Projeto e } \\
\text { Desenvolvimento do } \\
\text { Processo }\end{array}$ & $\begin{array}{l}\text { 4) Validação do } \\
\text { Produto e do } \\
\text { Processo }\end{array}$ & $\begin{array}{c}\text { 5) Retroalimentação, } \\
\text { Avaliação e Ação } \\
\text { Corretiva }\end{array}$ \\
\hline 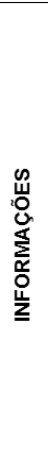 & $\begin{array}{r}\text { Relatc } \\
\text { Plan } \\
\text { Resulta } \\
\text { Testé } \\
\text { Anál } \\
\text { Criti }\end{array}$ & $\begin{array}{l}\text { orios, } \\
\text { os, } \\
\text { dos de } \\
\text { es e } \\
\text { ses } \\
\text { cas }\end{array}$ & $\begin{array}{l}\text { - Voz do Cliente } \\
\text { - - lano de Negócios/ } \\
\text { Estratégia de Marketing } \\
\text { - Dados de Benchmark do } \\
\text { Produto e Processo } \\
\text { - Premissas do Produto/ } \\
\text { Processo } \\
\text { - Estudos sobre a } \\
\text { Confiabilidade do Produto } \\
\text { - Objetivos do Projeto } \\
\text { - Metas de Confiabilidade e de } \\
\text { Qualidade } \\
\text { - Lista Preliminar de Materiais } \\
\text { - Fluxograma Preliminar do } \\
\text { Processo } \\
\text { - Lista Preliminar de } \\
\text { Caracteristicas Especiais de } \\
\text { Produto e Processo } \\
\text { - Plano de Garantia do Produto }\end{array}$ & $\begin{array}{l}\text { - FMEA de Projeto } \\
\text { - Plano de Verif. do Projeto } \\
\text { - Análises Criticas de Projeto } \\
\text { - Plano de Construção do } \\
\text { Protótipo } \\
\text { - Desenhos de Engenharia } \\
\text { - Especificaçōes da } \\
\text { Engenharia } \\
\text { - Especificações de Material } \\
\text { - Alteraçôes de Desenhos } \\
\text { - Especific açōes Requisitos } \\
\text { para Novos } \\
\text { Equipamentos, Ferramental e } \\
\text { Instalaçốns } \\
\text { - Caracteristicas Especiais do } \\
\text { Produto e do Processo } \\
\text { - Requisitos para } \\
\text { Meios de Medição/ } \\
\text { Equipamentos de Teste } \\
\text { - Formulário de } \\
\text { Comprometimento de } \\
\text { Viabilidade da Equipe }\end{array}$ & $\begin{array}{l}\text { - Padrões de Embalagem } \\
\text { - Análise Critica do Sistema } \\
\text { da Qualidade do Produto / } \\
\text { Processo } \\
\text { - Fluxograma do Processo } \\
\text { - Layout das Instalaçōes } \\
\text { - Matriz de Caracteristicas } \\
\text { - FMEA de Processo } \\
\text { - Plano de Controle de Pré- } \\
\text { Lançamento } \\
\text { - Instruçōes do Processo } \\
\text { - Plano de Análise dos } \\
\text { Sistemas de Medição } \\
\text { - Plano de Étudo Preliminar } \\
\text { da Capabilidade do Processo } \\
\text { - Especificações de } \\
\text { Embalagem }\end{array}$ & $\begin{array}{l}\text { - Resultado da Corrida Piloto } \\
\text { de Produção } \\
\text { - Avaliação de Sistemas de } \\
\text { Medição } \\
\text { - Estudo Preliminar da } \\
\text { Capabilidade do } \\
\text { Processo } \\
\text { - Aprovação de Peça de } \\
\text { Produção } \\
\text { - Testes de Validação da } \\
\text { Produçãao } \\
\text { - Avaliação de Embalagem } \\
\text { - Plano de Controle da } \\
\text { Produção } \\
\text { - Aprovacãão do Planejamento } \\
\text { da Qualidade } \\
\text { - Suporte da Gerência }\end{array}$ & $\begin{array}{l}\text { - Dados sobre a performance } \\
\text { estatistica das } \\
\text { caracteristicas definidas pelo } \\
\text { plano de controle } \\
\text { - Indicadores internos e } \\
\text { externos referentes à } \\
\text { satisfação do cliente }\end{array}$ \\
\hline \multirow{3}{*}{ 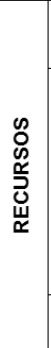 } & $\begin{array}{r}\text { Conce } \\
\text { Filos }\end{array}$ & \begin{tabular}{l|l} 
itos $/$ \\
ofia
\end{tabular} & \multicolumn{5}{|c|}{ Engenharia Simultânea } \\
\hline & $\begin{array}{l}\text { Técni } \\
\text { Conc }\end{array}$ & $\begin{array}{l}\text { cas / } \\
\text { itos }\end{array}$ & $\begin{array}{l}\text { - Benchmarking } \\
\text { - Indices de Confiabilidade } \\
\text { - Análise de PPM } \\
\text { - QFD }\end{array}$ & $\begin{array}{l}\text {-FMEA } \\
\text { - DFM/DFA } \\
\text { - QFD } \\
\text { - DOE } \\
\text { - Engenharia do Valor } \\
\text { - Análise de Elementos } \\
\text { Finitos } \\
\text { - Modelagem de Sólidos } \\
\text { - Planos de Confiabilidade } \\
\text { de Engenharia }\end{array}$ & $\begin{array}{l}\text { - FMEA } \\
\text { - DFM/DFA } \\
\text { - QFD } \\
\text { - DOE } \\
\text { - Ergonomia } \\
\text { - Poka-yoke }\end{array}$ & $\begin{array}{l}\text { - Indices de Capabilidade } \\
\text { - CEP } \\
\text { - R\&R } \\
\text { - Análise de PPM }\end{array}$ & $\begin{array}{l}\text { - CEP } \\
\text { - DOE } \\
\text { - Análise de PPM } \\
\text { - Benchmarking } \\
\text { - Análise de movimentos } \\
\text { - Ergonomia } \\
\text { - Poka-yoke }\end{array}$ \\
\hline & $\begin{array}{r}\text { Ferram } \\
\text { Siste }\end{array}$ & $\begin{array}{l}\text { entas / } \\
\text { mas }\end{array}$ & & GDET & CADICAE & & \\
\hline \multicolumn{3}{|c|}{ ORGANIZAÇÃO } & \multicolumn{5}{|c|}{$\begin{array}{l}\text { Abordagem por equipe multi-funcional (representantes da Engenharia, Manufatura, Controle de Material, Compras, Qualidade, } \\
\text { Vendas, Assistência Técnica, Subcontratados e Clientes).Necessidade de um líder para a equipe de projeto. }\end{array}$} \\
\hline
\end{tabular}

Figura 6 - Aplicação da estrutura conceitual de gestão do PDP com aprendizagem de "loop duplo" ao APQP 
- A aprendizagem dentro PDP necessita ser analisada dentro da ótica de que as atividades do PDP concorrem com as outras atividades existentes na empresa na disputa pelo escasso recurso da atenção das pessoas. A utilização da Tecnologia da Informação pode tornar esse recurso mais escasso ainda ou viabilizar sua melhor utilização (DAVENPORT e BECK, 2001). Isso implica em assegurar a participação das pessoas envolvidas no PDP sabendo gerenciar adequadamente a escassez de atenção humana.

\section{Aplicando a estrutura conceitual de gestão do PDP ao APQP}

O modelo do APQP tem sido adotado por um grande número de empresas sendo que, muitas vezes, os recursos investidos em sua implementação atingem valores expressivos. Trata-se de um modelo que vem se consolidando como referência tanto nos meios industriais como no âmbito do ensino e pesquisa em áreas como Engenharia de Produção e Engenharia de Produto. Dada a magnitude de sua projeção e suas proposições para a sistematização do PDP, o presente trabalho adota sua estrutura conceitual e metodológica como objeto de estudo. Até que ponto a iniciativa de estabelecer uma maneira mais disciplinada e estruturada no PDP pela adoção do "pacote" prescrito pelo APQP promove também a inserção e desenvolvimento da aprendizagem de "loop duplo" na organização?

O desenvolvimento desta capacidade depende da busca de certos objetivos-chave. Na Figura 6, o quadro localizado na parte superior aponta, em linhas gerais, o papel a ser cumprido pela gerência e pelos times de desenvolvimento no decorrer das fases de conceituação, execução e follow-up do PDP, na perspectiva de Hameri e Nihtilã (1998).

Na mesma figura, o quadro maior localizado na parte inferior sintetiza o "pacote" do APQP em termos dos quatro elementos que constituem um modelo de PDP, quais sejam: i) fases/atividades, ii) informação, iii) recursos, e iv) organização. As cinco etapas de um projeto de desenvolvimento admitidas pelo modelo do APQP (ver seção 2) são associadas às três fases consideradas por Hameri e Nihtilã (1998) e os documentos, técnicas, métodos, ferramentas, sistemas etc. prescritos pelo APQP para a condução das diferentes etapas de um projeto de desenvolvimento são apresentados no corpo do quadro maior.

A Figura 6 apresenta, portanto, as relações entre os objetivos que devem ser atendidos para a aprendizagem de "loop duplo" e o instrumental fornecido pelo APQP, sob uma perspectiva temporal.
Portanto, partindo-se da Figura 6, pode-se avaliar como em cada fase os elementos propostos pelo APQP podem contribuir para o atendimento dos objetivos de aprendizagem de "loop duplo" no desenvolvimento.

\subsection{A aprendizagem na fase de conceituação do produto}

Nesta fase, a gerência deve gerar um entendimento comum dos processos de desenvolvimento e de avaliação. Os times de desenvolvimento devem assegurar que os objetivos principais e os específicos do projeto sejam bem entendidos.

Para o atendimento destes objetivos o APQP dispõe de alguns elementos:

i. Os objetivos de projeto;

ii. As metas de confiabilidade e qualidade;

iii. A lista preliminar de características especiais de produto e processo, que merecem atenção e controle especial durante a manufatura;

iv. Plano de garantia do produto podendo conter os itens i, ii e iii, além de elementos como avaliação de requisitos de inovação tecnológica, complexidade, materiais, meio-ambiente, embalagem, serviço e manufatura ou qualquer outro fator que possa colocar o projeto em risco.

Estes quatro elementos fazem parte dos outputs desta fase. O APQP estabelece que os mesmos devem ser formalmente descritos e divulgados para o time de desenvolvimento.

Gonzalez e Miguel (2001) reportam que a implantação do APQP possibilitou a criação de uma linguagem comum de comunicação entre todos os setores participantes do desenvolvimento permitindo maior negociação entre os membros do time na definição dos prazos para o cumprimento das diversas fases desse processo.

Na fase de conceituação do produto, o APQP conduz à clara definição das diretrizes do projeto, estimula a reflexão e antecipação de aspectos críticos ao desenvolvimento, incute uma disciplina pela formalização destas considerações de modo a facilitar a interação entre os atores envolvidos no desenvolvimento e propicia uma melhoria na qualidade da comunicação. Assim, suporta os objetivos de aprendizagem tanto da gerência como do time de desenvolvimento. 


\subsection{A aprendizagem na fase de execução do desenvolvimento}

Esta fase corresponde à segunda, terceira e quarta etapas do APQP que têm como propósito garantir que os projetos do produto e do processo de produção atendam aos requisitos de desempenho e especificações de engenharia.

Aqui a gerência deve controlar as atividades do time obtendo um feedback on-line das mesmas enquanto que os times avançam no desenvolvimento do produto e do processo, respondendo e lidando imediatamente com os problemas que surgem. Nos ciclos de definição e resolução de problemas, os indivíduos envolvidos certamente aprendem com a própria experiência, contudo isso não implica na aprendizagem organizacional. Vale também ressaltar que este processo gera uma enorme quantidade e variedade de dados, informações e decisões que precisam ser organizadas e agregadas à base de conhecimentos da organização.

A proposta do APQP é justamente procurar disponibilizar para a gerência, de uma maneira estruturada e prescritiva, inúmeras informações sobre o projeto do produto e processo. Assim o modelo do APQP prescreve vários documentos como planos e relatórios, bem como testes que devem ser realizados e submetidos a uma análise crítica durante o desenvolvimento para fins de aprovação. Como exemplos de tais elementos podemos citar: FMEA de Projeto, Plano de Verificação do Projeto, Plano de Controle e Construção de Protótipo, Formulário de Compromisso da Equipe com a Viabilidade, Lista de Verificação da Qualidade do Produto/Processo, FMEA de Processo, Plano de Controle de Pré-Lançamento, Plano de Análise dos Sistemas de Medição, Plano de Estudo Preliminar da Capabilidade do Processo, Testes de Validação da Produção e Avaliação da Embalagem, entre outros (AIAG, 1995).

Mas até que ponto a simples introdução de diretrizes para a formalização dos conhecimentos promove efetivamente a aprendizagem da gerência e dos times?

Para que esta abordagem seja bem sucedida nas empresas, devemos considerar a necessidade das mesmas de serem capazes de compreender adequadamente os requisitos e ferramentas abarcadas pelo
APQP, bem como a necessidade de terem os recursos adequados para executar tais atividades. Neste sentido, uma pesquisa realizada por Abraham (1998) junto a uma amostra de fornecedores, revelou que, em muitas empresas, as pessoas envolvidas com PDP encontram dificuldades para implementar as práticas propostas pelo APQP. Os principais fatores inibidores seriam os seguintes:

- As pessoas podem não estar adequadamente treinadas para compreender a lógica do processo de planejamento da qualidade do produto. Ao não compreenderem esta lógica, elas se tornam alheias aos objetivos principais;

- As pessoas demonstram ter dificuldade em compreender os requisitos do texto do APQP. A interpretação do APQP pode ser vista como uma tarefa difícil; ${ }^{7}$

- As pessoas podem não estar adequadamente treinadas no ferramental prescrito e enfrentar dificuldades para aplicá-lo;

- Face à estrutura enxuta das empresas, ao alto volume de produtos desenvolvidos e à necessidade de cumprimento de prazos, algumas etapas do APQP acabam sendo parcialmente suprimidas.

\subsection{A aprendizagem na fase de follow-up}

Esta fase corresponde à última das cinco etapas concebidas pelo APQP. Trata-se da fase mais pobre em detalhes e informações no modelo do APQP.

Nela, cabe à gerência avaliar o desempenho do processo de desenvolvimento de produto identificando as áreas que precisam ou podem ser melhoradas. Já os times de desenvolvimento devem obter sugestões de melhoria para o produto desenvolvido e para o processo de desenvolvimento em si e ganhar experiência com as lições aprendidas. A implementação destas modificações deve ser acompanhada pela gerência, a quem cabe assegurar a eficácia dos esforços de aprimoramento.

Nesta fase, podem ser obtidos os três tipos de resultados apontados a seguir:

i. Redução da variação através de ações sobre os processos produtivos existentes;

7 Um técnico responsável pelo desenvolvimento do APQP em uma montadora conduziu um estudo para avaliar o nível de leitura de seu texto. Utilizando um software específico para este fim, constatou que seu texto requer um nível de leitura equivalente ao do segundo ano do ensino superior. Diante desta dificuldade, muitas empresas têm de recorrer à ajuda de consultores. 
ii. Partindo de estudos de satisfação do cliente, identificar deficiências no produto e obter maior aprovação tomando as medidas necessárias para corrigi-las;

iii. Melhoria da qualidade, do custo e da entrega ao cliente mediante investigação dos dados e problemas encontrados tanto na Entrega como na Assistência Técnica (AIAG, 1995).

Entretanto, para que o conhecimento gerado na busca de tais resultados após a fase de execução do desenvolvimento propriamente dito não fique circunscrito somente às pessoas que participaram do projeto em questão e seja útil para evitar a ocorrência das mesmas falhas em projetos futuros, é imperativo estabelecer um mecanismo que incorpore aquilo que foi aprendido à base de conhecimento da empresa. Este mecanismo deve também facilitar o reaproveitamento deste conhecimento num estágio mais à montante do processo de desenvolvimentos em projetos subseqüentes. Uma organização pode até estar conforme o modelo APQP mas sem este último mecanismo corre o risco de desperdiçar os esforços dedicados e ainda permanecer na aprendizagem de "loop único".

\section{Considerações gerais sobre a aprendizagem de "loop duplo" no APQP}

Após a discussão analítica do modelo APQP na seção anterior, são apresentadas a seguir algumas considerações gerais sobre as possibilidades da sua adoção contribuir para a aprendizagem de "loop duplo".

Um primeiro aspecto a ser levantado sobre esta questão é o caráter compulsório com que o APQP normalmente é implementado nas empresas. ${ }^{8}$ Ao implementarem o APQP, as empresas (ex.: fornecedores de primeira e segunda camadas das montadoras) devem adotar um conjunto mínimo de requisitos, independentemente da sua responsabilidade pelo projeto do produto. Neste sentido, não se considera a necessidade de reduzir ou amenizar a aplicação de alguns requisitos para produtos bastante simples ou para produtos projetados pelo cliente que apenas necessitam de algumas modificações. Além disso, os cronogramas de implementação comumente apertados acabam prejudicando a qualidade das atividades realizadas (ABRAHAM, 1998).
Um segundo aspecto é que o APQP traz consigo a utilização de várias técnicas e ferramentas. A equipe de desenvolvimento deve conhecer e utilizar a Análise dos Modos de Falha e seus Efeitos (FMEA), Análise dos Sistemas de Medição (MSA), Benchmarking, Índices de Capabilidade, Sistemas à Prova de Erros (Mistake Proofing/Poka-yoke), Fluxograma e Controle Estatístico de Processo (CEP). Além destas, a norma QS-9000, nas prescrições referentes ao Controle de Projeto, determina que dependendo das circunstâncias a empresa deve se qualificar também nas seguintes técnicas e ferramentas: Delineamento de Experimentos (DOE), Desdobramento da Função Qualidade (QFD), Engenharia de Valor, Dimensionamento Geométrico e Tolerância (GD\&T), Análise de Elementos Finitos, Modelagem de Sólidos, Técnicas de Simulação, CAD/ CAE, Planos de Confiabilidade de Engenharia, Projeto para Manufatura (DFM) e Projeto para Montagem (DFA) (ABRAHAM, 1998, p.110). Muitas destas não são conhecidas e/ou dominadas pelos times de desenvolvimento. Portanto, para que uma empresa possa aplicar adequadamente o APQP, deve despender recursos e tempo para capacitar seu pessoal nas mesmas. ${ }^{9}$ Isto pode ser um fator bastante restritivo para sua implementação. Por outro lado, na medida em que a própria assimilação dos requisitos do APQP demanda esforços para aquisição de novos conhecimentos e capacitação em novas práticas, a sua adoção em si reforça a necessidade de tornar mais consistente o processo de aprendizagem organizacional.

Um outro aspecto que merece ser salientado é que a adoção do APQP implica em privilegiar as atividades de planejamento. Segundo Stamatis (1998), para muitas organizações, a priorização do planejamento somente ocorre após uma grande mudança cultural na maneira de conduzir as atividades de desenvolvimento. Portanto, as empresas devem evitar armadilhas que inibam esta mudança. As principais armadilhas encontradas pelas empresas segundo este autor são:

i. Falta de suporte da gerência e falta de comprometimento da mesma com o planejamento;

ii. Alocação de um tempo insuficiente para as atividades de planejamento;

iii. Convivência com práticas do tipo "apagar incêndios", reconhecendo as pessoas mobilizadas como "heróis" em detrimento justamente dos profissio-

8 O APQP não é uma aplicação obrigatória, mas o fornecedor deve utilizá-lo como um manual de referência; entretanto, alguns de seus requisitos específicos devem ser implementados integralmente.

9 Algumas destas técnicas exigem uma formação anterior para que sejam devidamente compreendidas. 
nais que planejam as atividades de maneira correta visando a prevenir tais práticas paliativas.

Um quarto aspecto da adoção do APQP pelas empresas, ainda segundo Stamatis (1998), é a exigência da implantação de times multifuncionais para o desenvolvimento. Esta abordagem promove o compartilhamento do conhecimento e expertise de diferentes áreas funcionais e especialistas possibilitando oportunidades para a geração de soluções e adoção de melhorias no projeto e/ou no processo. Contudo, tal abordagem requer uma estrutura organizacional e de comando que propicie a formação de times multifuncionais e suporte suas ações. Nas empresas que continuam com uma estrutura rígida, departamentalizada e centralizadora, a multifuncionalidade poderá ser obstruída.

Finalmente, vale observar que um projeto típico de desenvolvimento pode gerar centenas de documentos e conter milhares de dados. Caso o projeto seja conduzido passo a passo em conformidade com o APQP isso pode se acentuar. Portanto, a adoção do APQP requer um gerenciamento adequado de documentos e dados. Diante desta necessidade, várias empresas têm-se tornado usuárias de softwares que permitem gerenciar apropriadamente os documentos e dados gerados ao longo do desenvolvimento. Vale lembrar que uma mudança qualquer em um documento pode implicar na revisão de outros e na necessidade de divulgação, análise e aprovação por várias áreas, pessoas e, até, fornecedores ou clientes (ADAMS, 2000; MITCHELL, 2001). Conseqüentemente, para uma efetiva implementação do APQP, faz-se necessário estruturar um sistema de gerenciamento da informação que possa suportar todo este complexo processo de gestão de conhecimento retendo a atenção das pessoas envolvidas nas diferentes etapas do PDP. Naturalmente, isto implica na necessidade das empresas de investir recursos significativos na aquisição de equipamentos e softwares, bem como no treinamento de seu pessoal para se capacitar na exploração dos recursos proporcionados pelas Tecnologias de Informação com tal propósito.

Os aspectos aqui discutidos sugerem que a iniciativa de implantar o APQP numa organização e o posterior processo de realização de projetos de desenvolvimento em conformidade com o modelo do APQP têm implicações distintas sobre a aprendizagem de "loop duplo". Num primeiro momento, a adoção do APQP tende a ser mais um fator motivador da aprendizagem. Já a sua aplicação em regime pode ser um fator promotor da aprendizagem de "loop duplo". De qualquer forma, o APQP por si só não seria um fator suficiente.

\section{Conclusão}

O PDP em muitas organizações ainda se situa no estágio da aprendizagem de "loop único". As considerações colocadas neste trabalho podem ser úteis aos gestores de desenvolvimento empenhados em conduzir o PDP de sua organização a um estágio evolutivo superior.

A formulação e difusão de modelos referenciais como o APQP têm como motivação tornar mais robusto o PDP e melhorar o desempenho de suas atividades. Contudo, como discutido ao longo das seções 5 e 6, a aprendizagem de "loop duplo" nem sempre é assegurada pela adoção do APQP como modelo referencial de planejamento, organização e condução do PDP. O estabelecimento de um ambiente de aprendizagem de "loop duplo" requer a implementação de mecanismos e recursos complementares.

Como extensão do presente trabalho, sugere-se pesquisar se a adoção de um outro modelo referencial (e.g. PMBOK, ${ }^{10} \mathrm{DFSS}^{11}$ ) suportaria de forma mais favorável a aprendizagem de "loop duplo" no ambiente de desenvolvimento de produtos.

\section{Referências}

ABRAHAM, M. O futuro do desenvolvimento de produtos e da cadeia de fornecimento da indústria automobilística. São Paulo, 1998. 175 p. Tese (Doutorado) - Escola Politécnica da Universidade de São Paulo. Departamento de Engenharia de Produção.

ADAMS, L. Software helps you mind your APQPs. Quality, p.42-45, Out. 2000.

AIAG, APQP - Advanced Product Quality Planning and Control Plan - Chrysler, Ford and General Motors, 1995.

ARGYRIS, C. Single-loop and double-loop models in research on decision making. Administrative Science Quarterly, v.21, p.363-377, Sept. 1976.

ARGYRIS, C. Double loop learning in organizations. Harvard Business Review, p.115-124, Sept.-Oct. 1977.

CASTELLS, M. A sociedade em rede. São Paulo: Paz e Terra, 1999, p.21-172.

CLARK, K.B.; FUJIMOTO, T. The parameters of performance: lead time, quality, and productivity. In: Product Development Performance Strategy, Organization, and Management in the World Auto

10 Project Management Body of Knowledge

11 Design for Six Sigma 
Industry. Boston: Harvard Business School Press, 1991, p.67-95.

CLARK, K.B.; WHEELWRIGHT, S.C. Revolutionizing product development: quantum leaps in speed, efficiency, and quality. New York: The Free Press, 1992.

DAVENPORT, T.H.; BECK, J.C. A economia da atenção. Rio de Janeiro: Campus, 2001.

GONZALEZ, J.C.S.; MIGUEL, P.A.C. APQP: uma ferramenta para estruturação do desenvolvimento do produto. In: CONGRESSO BRASILEIRO DE GESTÃO DO DESENVOLVIMENTO DE PRODUTO. Anais do II CBGDP. São Carlos, 2000.

GRIFFIN, A.; PAGE A.A. PDMA Success Measurement Project: Recommended Measures for Product Development Success and Failure. Journal of Product Innovation Management, v.13, p. 478-496, 1996.

HAMERI, A.; NIHTILÃ, J. Data-based learning in product development. Scandinavian Journal of Management, v.14, n.3, p.223-238, 1998.

LUPO, C. ISO/TS 16949 the clear choice for automotive suppliers. Quality Progress, Oct. 2002.

McGRATH, M.E. Setting the pace in product development: guide to product and cycle-time excellence. Butterworth-Heinemann, 1996.

MITCHELL, E. Web-based APQP keeps everyone connected. Quality, p.40-44., July 2001.
MUNRO, R.A. Future of APQP and PPAP in Doubt. Quality, p.28-32, Jan. 2002.

NEVIS, E.C.; DIBELLA, A.J.; GOULD, J.M.

Understanding Organizations as Learning Systems. Sloan Management Review, p.73-84, Winter 1995.

PINE II, B.J. Personalizando Produtos e Serviços: Customização Maciça. São Paulo: Makron Books, 1994.

PORTER, M.E.; MILLAR, V.E. Como a informação lhe proporciona vantagem competitiva. In: Revolução em tempo real - Gerenciando a tecnologia da informação, $2^{\mathrm{a}}$ ed., Rio de Janeiro: Campus, 1997.

PROBST, G. et al. Gestão do conhecimento: os elementos construtivos do sucesso. Porto Alegre: Bookman, 2002.

SILVA, S.L.; AMARAL, D.C.; ROZENFELD, H. Portais da internet como ferramenta para a gestão de conhecimentos no desenvolvimento de produtos. In: CONGRESSO BRASILEIRO DE GESTÃO DO DESENVOLVIMENTO DE PRODUTO. Anais do II CBGDP. São Carlos, 2000.

STAMATIS, D. H. Advanced Quality Planning: $a$ commonsense guide to $A Q P$ and $A P Q P$. New York: Quality Resources, 1998.

Submetido em abril/2004

Aprovado em agoosto/2004 